\title{
A narratividade na formação continuada de professores para uma educação inclusiva
}

\author{
The narrativity in continuing teacher training for \\ inclusive education
}

\section{La narratividad en la formación continua de profesores para una educación inclusiva}

José Eduardo de Oliveira EVANGelista LanUtI (iDa

MARIA ISABel SAMPaIO DIAS BaptISTA (iD)

\section{Resumo}

A partir de um estudo bibliográfico, analisaram-se os itinerários e resultados de duas pesquisas de Doutorado, defendidas em 2018 e 2019 no Laboratório de Estudos e Pesquisas em Ensino e Diferença (LEPED), da Universidade Estadual de Campinas (UNICAMP). A necessidade de encontrar caminhos que possibilitam uma formação continuada de professores para uma educação inclusiva originou essas investigações. Sabe-se que a formação inicial não é suficiente para preparar os professores para o desenvolvimento de um trabalho pedagógico inclusivo, uma vez que as demandas, nesse sentido, se atualizam constantemente. Assim sendo, os objetivos deste texto foram analisar as contribuições da valorização da narratividade dos professores participantes de dois processos de formação continuada, um presencial e outro à distância, e identificar quais os pontos em comum entre os dois processos que levaram os participantes a uma reflexão e reconstrução de práticas pedagógicas a fim de incluir todos os estudantes na sala de aula comum. Concluiu-se que, em ambas as teses, a valorização da subjetividade dos professores participantes e o fundamento na Política Nacional de Educação

\footnotetext{
a Universidade Federal de Mato Grosso do Sul (UFMS), Três Lagoas, MS, Brasil. Doutor em Educação, e-mail: eduardo.lanuti@ufms.br

b Universidade Estadual de Campinas (UNICAMP), Campinas, SP, Brasil. Doutora em Educação, e-mail: belbaptista@gmail.com
} 
Especial na Perspectiva da Educação Inclusiva (PNEEPEI, BRASIL, 2008) foram pontos determinantes para o entendimento dos professores sobre o que é a inclusão e suas demandas. Ao narrarem as suas experiências docentes durante as duas formações investigadas, os participantes repensaram o modo como concebiam o ensino, a aprendizagem e a deficiência e entenderam que o papel de uma escola inclusiva é o de promover a plena participação de cada aluno, mas segundo a sua capacidade, sem a pretensão de que ocorra uma homogeneização da aprendizagem.

Palavras-chave: Narratividade. Formação de professores. Inclusão Escolar.

\begin{abstract}
Based on a bibliographic study, the itineraries and results of two PhD studies defended in 2018 and 2019 at the Laboratory of Studies and Research in Teaching and Difference (LEPED) at the State University of Campinas (UNICAMP) were analyzed. The need to find ways that enable continuing education of teachers for inclusive education gave rise to these investigations. It is known that initial training is not enough to prepare teachers for the development of inclusive pedagogical work since demands, in this sense, are constantly updated. Therefore, the objectives of this text were to analyze the contribution values of the narrativity of the teachers participating in two processes of continuing education, one in person and the other one at distance. It also seeks to identify what the two processes have in common that led the participants to reflection and reconstruction of pedagogical practices, in order to include all students in the standard classroom. It was concluded that, in both theses, the valorization of the subjectivity of the participating teachers, as well as the foundation in the National Policy of Special Education in the Perspective of Inclusive Education (PNEEPEI, BRASIL, 2008), were decisive points for the teachers' understanding of what inclusion is and its demands. When narrating their teaching experiences during the two investigated courses, the participating teachers rethought the way they conceived teaching, learning and disability. It was understood that the role of an inclusive school is to promote full participation of each student. Yet, it should be according to their capacity and without pretension that homogenization of learning might occur.
\end{abstract}

Keywords: Narrativity. Teacher training. School inclusion.

\title{
Resumen
}

De un estudio bibliográfico, fueron analizados los itinerarios y resultados de dos investigaciones doctorales, defendidos en 2018 y 2019 en el Laboratorio de Estudios e Investigaciones en Enseñanza y Diferencia (LEPED), de la Facultad de Educación (FE), de la Universidad Estatal de Campinas (UNICAMP). La necesidad de encontrar caminos, que permitan una formación continua de profesores para una educación inclusiva, originaron estas investigaciones. Se sabe que la formación inicial no es suficiente para preparar a los profesores para el desarrollo del trabajo pedagógico inclusivo, ya que las demandas, en este 
sentido, se actualizan constantemente. Siendo así, los objetivos de este texto fueron analizar los aportes de la apreciación de la narratividad de los docentes que participan em dos procesos de formación continua, uno presencial e y otro a distancia, e identificar cuáles son los puntos comunes entre los dos procesos que llevaron a los participantes a una reflexión y reconstrucción de prácticas pedagógicas para incluir a todos los estudiantes en el aula común. Se concluyó que, en ambas tesis, la valorización de la subjetividad de los profesores participantes, así como la base de la Política Nacional de Educación Especial en la Perspectiva de la Educación Inclusiva (PNEEPEI, BRASIL, 2008) fueron puntos decisivos para la comprensión de los profesores de lo que es la inclusión y sus demandas. Al narrar sus experiencias de enseñanza durante las dos formaciones investigadas, los profesores participantes repensaron la forma en que concibieron la enseñanza, el aprendizaje y la discapacidad y entendieron que el papel de una escuela inclusiva es promover la plena participación de cada estudiante, pero de acuerdo con su capacidad, sin la pretensión de que se produce la homogeneización del aprendizaje.

Palabras clave: Narratividad. Formación de Profesores. Inclusión Escolar.

\section{Introdução}

O ensino nas escolas vem sendo concebido como uma transmissão de saberes prontos que precisam ser decalcados pelos alunos. Em decorrência, a aprendizagem é reduzida ao saber, à recognição — um processo que tenta, incessantemente, controlar aquilo que é livre por natureza: a aprendizagem, a criação.

Por essa lógica embrutecedora, construiu-se a idealização de um aluno que, ao corresponder às exigências da escola, serviria de modelo aos demais. Submeteu-se, então, a diferença de alguns estudantes a uma característica que, supostamente, torna-os “diferentes" dos demais (MANTOAN, 2008), caso eles não sejam "bons pretendentes" ao ícone instituído, conforme denunciou Deleuze (2000). Diante disso, as práticas pedagógicas e as pesquisas educacionais, na maioria das vezes, vêm se deixando contaminar pela pretensiosa ideia de que é possível verificar a aprendizagem, definir como os alunos precisam ser e quais habilidades eles devem desenvolver para reproduzir as verdades incontestáveis da escola.

O Laboratório de Estudos e Pesquisas em Ensino e Diferença (LEPED), vinculado à Faculdade de Educação da Universidade Estadual de Campinas (UNICAMP), desde a sua fundação em 1996, dedica-se ao ensino inclusivo. Pioneiro no Brasil na defesa incondicional da educação para todos, o LEPED tem 
desenvolvido pesquisas que articulam os saberes construídos na Universidade à realidade das escolas brasileiras, em todos os níveis, etapas e modalidades de ensino.

As pesquisas realizadas no LEPED se baseiam em fundamentos que valorizam a produção de sentidos para os processos de ensino. Partem, necessariamente, do direito que cada aluno tem de se desenvolver na escola comum segundo a sua capacidade cognitiva, curiosidade, interesse e desejo - - aspectos que, quase sempre, são ignorados nas escolas.

A narratividade tem sido utilizada em vários estudos produzidos nesse Laboratório. Por meio dela, organizam-se os fatos vividos sem, necessariamente, obedecer a uma ordem cronológica, uma lógica consensual ou uma análise cartesiana da realidade escolar. A narratividade valoriza a curiosidade, interesse, desejo de cada ator do processo educacional e, portanto, está "intimamente relacionada ao processo de criação de sentidos às nossas experiências" (LANUTI, 2019, p.32).

Ao narrar suas experiências, cada pessoa apresenta sentidos ao que lhe afeta, conforme Baptista (2018). Acreditamos que a valorização da narratividade dos sujeitos possa contribuir para a reflexão dos professores e alunos e, consequentemente, para a construção de uma escola inclusiva.

Neste artigo, analisaremos as contribuições da valorização da narratividade dos professores participantes de dois processos de formação continuada, um presencial e outro à distância. Buscaremos, ainda, identificar o que levou os envolvidos nas duas experiências formativas à reflexão e construção de novas práticas pedagógicas a fim de incluir todos os estudantes na sala de aula comum.

\section{Movimentos de professores em formação continuada: um estudo pela narratividade}

A tese de Doutorado defendida por Baptista (2018) teve como universo de investigação uma formação continuada docente a distância. Uma rede social foi especialmente criada para o desenvolvimento da pesquisa. Ela denominou-se "Todos Nós em Rede" (TNR).

O problema delimitado pela pesquisadora esteve ligado aos processos de formação docente a distância, vivenciados pelos professores participantes na vigência 
da Política Nacional de Educação Especial na perspectiva da educação Inclusiva (PNEEPEI, BRASIL, 2008). De modo geral, cursos de formação de professores em Atendimento Educacional Especializado (AEE) contam com estruturas inflexíveis, conteudistas, mantendo relações hierarquizadas, entre seus participantes. Em suma, são organizados de modo a perpetuar dependências entre professores e seus formadores. A iniciativa do TNR foi inédita, uma vez que essa formação, em nenhum ponto, se confundiu com as propostas veiculadas pelos cursos de formação a distância.

As questões formuladas para a investigação foram as seguintes: i) O TNR oferecia condições para que os professores ultrapassassem uma cultura escolar de baixa autonomia e dependência? ii) Ele oferecia condições para que os participantes trocassem ideias, tomassem decisões para atender seus alunos, resolvessem problemas de forma colaborativa e, em consequência, aprimorassem a prática pedagógica? iii) Os professores conseguiriam se apropriar desse espaço de formação continuada autônoma, conforme o TNR propunha? (BAPTISTA, 2018, p. 40).

Diante desses questionamentos, o objetivo da pesquisadora foi conhecer como onze professores participantes se apropriaram do caráter autônomo de formação, oferecido pela rede TNR, para compartilhar dúvidas e resolver problemas a partir da sua diferença.

No TNR, os professores foram convidados a ser responsáveis pela sua própria formação. Eles não eram considerados pessoas idealizadas para as quais os recursos da rede eram primeiramente testados e depois disponibilizados. Os participantes eram coautores do projeto da rede. As Figuras 1 e 2, a seguir, mostram como se deu o processo de construção colaborativa do TNR. 
Figura 1- Desenho coletivo - técnica utilizada de desenho coletivo e participativo da futura rede TNR

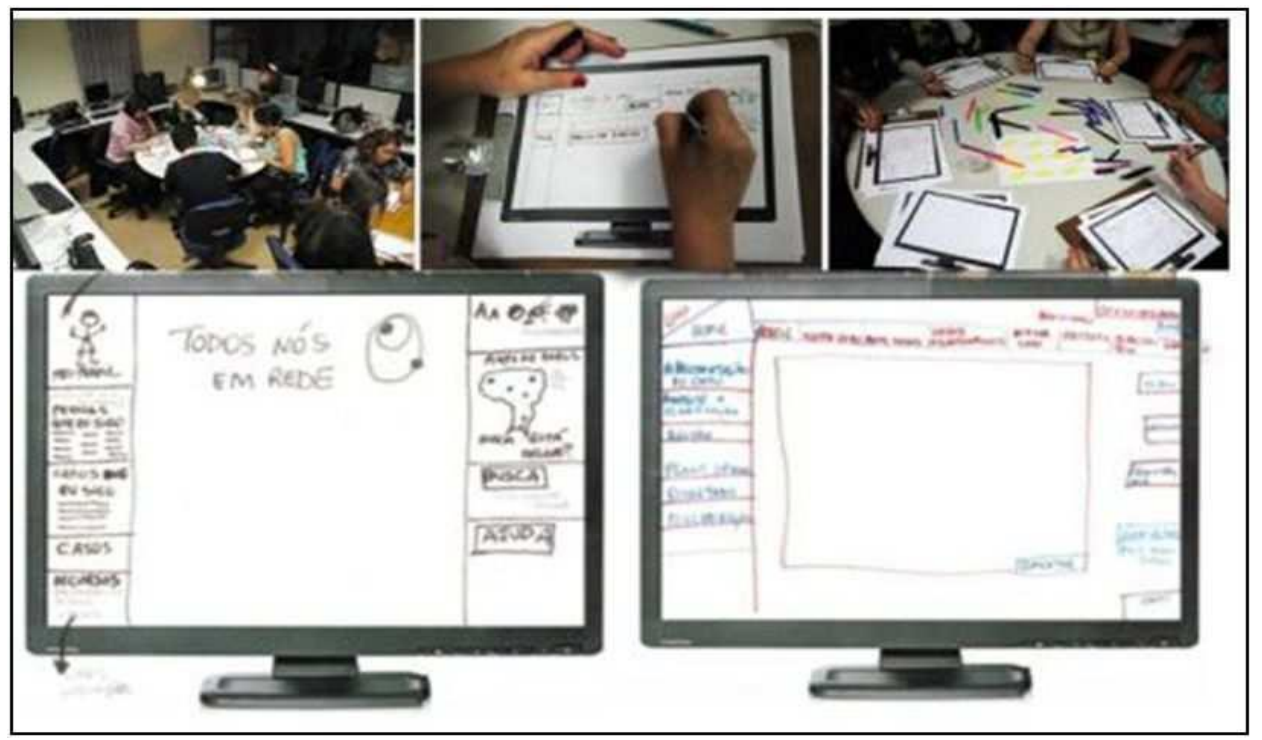

Fonte: Baptista (2018).

Pode-se observar, na Figura 1, como o TNR realmente nasceu dos anseios dos próprios docentes que eram os participantes ativos da rede que surgiria mais tarde. A partir dos desejos expressos nos desenhos dos professores, em 2011, a primeira versão da rede foi disponibilizada na internet, conforme a Figura 2, a seguir:

Figura 2 - Primeira versão da rede TNR disponibilizada na internet em novembro de 2011

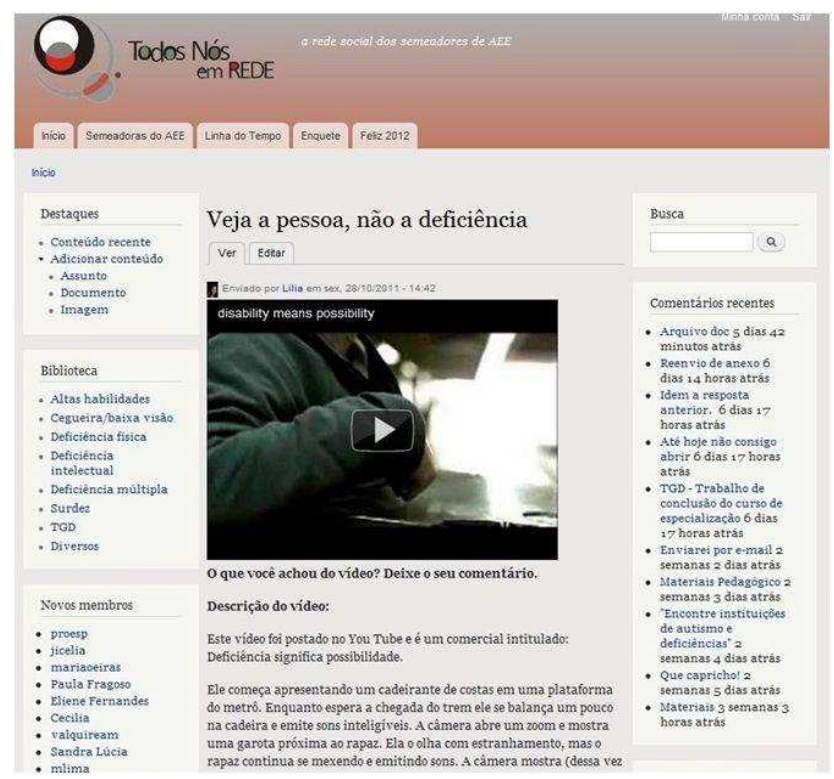

Fonte: Baptista (2018). 
A criação do TNR, com a contribuição ativa das professoras foi, portanto, uma experiência realmente inédita no Brasil, justamente por considerar a subjetividade dos envolvidos: seus desejos, objetivos, dúvidas e habilidades — o que quase nunca é considerado em processos formativos.

\section{Embasamento teórico}

O embasamento teórico que fundamentou essa pesquisa esteve relacionado à concepção e design participativo do TNR, com os autores Rocha e Baranauskas (2003). Outros autores auxiliaram a pesquisadora a compreender, pela narratividade, como ocorria a atuação dos professores na rede criada. Benjamim (1994) foi o autor que colaborou com o conceito de narrativa; Larrosa (2015) trouxe questionamentos sobre a importância da experiência em educação; Mantoan (2006) acrescentou problematizações cruciais sobre a inclusão; Moraes (1999) auxiliou a estruturar o fazer de uma pesquisa narrativa e Clandinin e Connelly (2015) ampliaram a visão sobre pesquisa narrativa em educação e suas possibilidades. Outro importante referencial foi o fundamento na PNEEPEI (2008), que trouxe o entendimento dos professores das demandas do AEE e da educação inclusiva.

\section{Caminho metodológico da formação}

A princípio, um grupo de vinte e oito professoras de AEE atuantes em diferentes regiões do país foi formado para compor o grupo de trabalho dentro do TNR. Segundo Baptista (2018, p. 51):

Para a escolha desse grupo inicial foram adotados alguns requisitos: i) ter familiaridade com tecnologia (ser digitalmente alfabetizado); ii) ser proativo, ter perfil investigativo e interesse no próprio aprendizado; c) reconhecer o benefício de participar do processo formativo. Outro critério para a seleção foi a localização geográfica da professora, ou seja, pelo menos uma pessoa representaria cada Unidade Federativa.

Das vinte e oito professoras colaboradoras na construção do TNR, onze voluntárias participaram desta pesquisa ${ }^{1}$. Partiu-se de narrativas produzidas por elas

\footnotetext{
1 Pesquisa aprovada pelo Comitê de Ética em Pesquisa (CEP) da UNICAMP. Número CAAE: 0647.0.146.000-11
} 
diante das dificuldades sobre inclusão escolar, especificamente em relação à natureza do AEE. Em sua maioria, estas contribuições vieram de comentários escritos em fóruns de discussão e atividades feitas a distância em reuniões via Gtalk. Também contamos com dois encontros presenciais com estas onze professoras na UNICAMP, com o objetivo de avaliar coletivamente a construção do TNR. Alguns depoimentos puderam ser filmados e registrados em desenhos, avaliações, respostas a questionários e outras fontes.

Enfrentaram-se desafios, tais como: trazer para o campo investigativo as narrativas das professoras e da pesquisadora, sem, contudo, empobrecê-las com explicações excessivas e articular todo esse material aos fundamentos teóricos escolhidos, discutindo qual o lugar da pesquisadora no processo, uma vez que ela também participava do estudo.

As narrativas docentes foram usadas de modo reflexivo pela pesquisadora que, por sua vez, criou narrativas para interpretar os problemas vivenciados pelas participantes. A metodologia fez seu caminho narrativo e a teoria esteve, ao longo de todo o texto, de modo ubíquo. Clandinin e Connely (2015, p. 73) afirmam, sobre o lugar da teoria na pesquisa, que "os formalistas começam a pesquisa pela teoria, enquanto os pesquisadores narrativos tendem a começar com a experiência assim como é expressa em histórias vividas e contadas".

Benjamim (1994), sobre a narratividade, adverte que "quase nada do que acontece está a serviço da narrativa, e quase tudo está a serviço da informação. Metade da arte narrativa está em evitar explicações” (BENJAMIN, 1994, p. 203). Nesta direção, foi fundamental a colaboração de Moraes (1999, p. 81) para o estudo referido, uma vez que, segundo este autor, a narrativa não é simplesmente "narrar fatos", pois:

[...] permite uma tomada reflexiva, identificando fatos que foram, realmente, constitutivos da própria formação. Partilhar [como pesquisador] histórias de vida permite a quem conta a sua história, refletir e avaliar um percurso compreendendo o sentido do mesmo entendendo as nuanças desse caminho percorrido e reaprendendo com ele. $E$ a quem ouve (ou lê) a narrativa permite perceber que a sua história se entrecruza de alguma forma (ou em algum sentido/lugar) com aquela narrada (e/ou com outras); além disso, abre a possibilidade de aprender com as experiências que constituem não somente uma história, mas o cruzamento de umas com as outras. 
A pesquisadora do LEPED observou que o sistema TNR foi capaz de oferecer condições para que as professoras participassem trocando ideias, tomando decisões e, assim, resolvendo colaborativamente os problemas. A partir da análise dos dados, conseguiu-se detectar diferentes modos de apropriação do TNR - o que comentaremos a seguir.

\section{Alguns resultados}

O TNR trouxe a cada participante, inclusive à pesquisadora, descobertas, inquietações, acontecimentos, estudos de casos, dificuldades e possibilitou incontáveis conexões — um modo de ampliar as experiências pedagógicas. Neste sentido, o TNR era aquele "algo que trazia o exterior, o aberto". Ele era "o real que era sempre mais e outra coisa!” (LARROSA, 2015, p.106).

A análise dos dados permitiu à pesquisadora detectar diferentes modos de apropriação do sistema TNR por parte das professoras. Ao estudar as narrativas, bem como o acesso às ações de cada uma delas dentro do TNR, foi possível concluir que a estrutura inovadora desta rede não foi suficiente para garantir a participação autônoma de todas as envolvidas. Baptista (2018) verificou, a partir das narrativas das professoras, que múltiplas razões se interpuseram entre o convite feito ao grupo e sua efetiva participação.

Glória, por exemplo, revelou o medo que sentia em expor suas ideias. Segundo seus relatos, sua angústia estava relacionada ao medo de represálias políticas e físicas que ela sofria por defender a educação inclusiva na pequena comunidade em que vivia. Tal comunidade apresentava altos índices de violência e um sistema educacional que não admitia questionamentos a respeito de práticas segregacionistas que ocorriam na rede. Depois de sofrer ameaças de morte e ter que mudar de casa, Glória relatou que evitava se expor nas reuniões de formação em sua escola e, também, no TNR. Sobre essa situação, Glória revelou:

Eu não postei casos porque eu não quero me expor, só por isso. Porque eu sei que se eu fizer isso vai se virar contra mim. Já vi de tudo acontecer! O governo que está aqui é fogo! Sei como são as coisas, se eu começar a meter nos casos, vão começar a dizer que eu só faço intervenção para criticar (BAPTISTA, 2018, p. 185). 
Apesar dos receios de Glória em se manifestar no TNR ela se dizia decepcionada com o nível dos comentários das colegas e se posicionava ativamente na rede sobre o que achava necessário.

Com Larrosa (2015), a pesquisadora refletiu que havia um "enjaulamento" da professora com a sua própria experiência. Para Glória, era inalcançável sair dos encadeamentos punitivos da escola e isso impedia sua liberdade de expressão. Fato é que, por meio da narratividade, ela encontrou uma maneira de participar da formação sem expor seus casos, mas comentando as experiências das colegas a partir do que lhe afetava.

Por outro lado, algumas professoras atuaram livremente na rede, sem preocupações. Quando indagada pela pesquisadora sobre a publicação de casos de estudo de AEE no TNR, a professora Mayra respondeu:

Olha, sobre o receio de postar, na verdade, eu não concordo muito não. Eu só não coloco mais casos lá porque tenho medo de ser criticada exatamente por isso pelas colegas!! (risos) Eu selecionei alguns pra não colocar todos! Porque pensei: daqui a pouco vou levar uma bronca delas! Poxa, que professora é essa que tem tanto caso, e tanta dúvida? (BAPTISTA, 2018, p. 187).

Baptista (2018) revelou que outra professora, Cândida, não tinha receio de expor aos demais colegas os problemas que vivenciava na escola. Ela sabia que poderia ser criticada pelo excesso de casos que publicava, contudo, a necessidade de aprender fez com que se abrisse para as colegas. Quando indagada sobre o receio de expor seus problemas no TNR, a professora afirmou:

Nunca tive receio dos problemas da nossa realidade porque nós temos que adaptar um monte de coisas, horários, deslocamentos. Temos que adaptar muitas coisas à nossa realidade porque senão nossos alunos não comparecem ao AEE e não é isso que a gente quer não! Pra mim é uma honra enorme poder falar isso porque essa é a minha realidade e não preciso esconder isso não! Se não fizermos essas adaptações à realidade não daremos condições e oportunidade desses alunos de participar do AEE. Sabe eu acho até que coloquei poucos casos... (risos) (BAPTISTA, 2018, p. 190).

Conforme dito anteriormente, os participantes da referida tese vivenciaram uma experiência coletiva inédita — a construção de uma rede de formação na internet a partir de uma proposta de desenho participativo (BARANAUSKAS; ROCHA, 
2003). Essa experiência, que resultou em uma mudança nas concepções e práticas docentes sobre a inclusão, foi possível com a valorização da narratividade das professoras participantes.

\section{A reconstrução do ensino a partir da produção de acontecimentos pela narratividade}

A tese de Doutorado ${ }^{2}$ defendida por Lanuti (2019) também teve como universo de investigação uma formação docente em serviço, contudo, uma formação presencial. Os participantes foram professores pedagogos que ensinam Matemática nos anos iniciais do ensino fundamental em escolas da zona rural e urbana.

O problema vivenciado pelo pesquisador (formador desse grupo) foi a dificuldade que os professores tinham de entender que ensinar Matemática (e outras disciplinas) em uma concepção inclusiva não dizia respeito a uma individualização do ensino para alguns alunos. Em decorrência, o objetivo estabelecido para a investigação foi analisar as contribuições da formação docente no entendimento do que é um ensino inclusivo.

A ideia do formador foi organizar um espaço no qual os professores pudessem compartilhar, semanalmente, seus desejos e dificuldades em relação ao ensino inclusivo. Ao refletirem sobre suas práticas e relatarem para os colegas o modo de conceber o ato pedagógico, os professores tinham oportunidades de repensar o ensino a fim de garantir que todos os alunos participassem das aulas, segundo as suas capacidades. Partiu-se do princípio que, ao superar o individualismo que, na maioria das vezes é característico da atividade docente, os professores teriam mais oportunidades de aprender com seus colegas.

Os trinta e cinco participantes organizaram-se em grupos menores, de acordo com o ano para o qual lecionavam. Os grupos foram assim constituídos: dez professores do $1^{\circ}$ ano, dezesseis dos $2^{\circ}$ e $3^{\circ}$ anos e nove dos $4^{\circ}$ e $5^{\circ}$ anos. Dessa forma, puderam olhar mais especificamente tanto para as necessidades docentes quanto para as de seus alunos, respectivamente.

\footnotetext{
2 Financiada pela Fundação de Amparo à Pesquisa do Estado de São Paulo (FAPESP). 
A condução desses encontros, os temas neles abordados, as estratégias de ensino criadas, o referencial adotado e os métodos de reflexão desenvolvidos foram construídos, colaborativamente, entre formador/pesquisador e professores, a partir das necessidades que o grupo apresentava no percurso de desenvolvimento desta experiência.

\section{Embasamento teórico}

Os fundamentos teóricos que sustentaram as discussões estiveram relacionados à filosofia de Gilles Deleuze. A escolha deste referencial se justifica pela necessidade dos professores, identificada pelo formador, de estudar questões de fundo da inclusão escolar. Dentre estas, a diferença que, por Deleuze, não é interpretada como um traço meramente externo ao ser humano, como a cor da pele, espécies, gênero ou qualquer característica, critério ou atributo que possibilita comparações e classificações dos sujeitos.

Para Deleuze $(1988 ; 2000)$, a diferença é interior a cada pessoa, diz respeito à sua singularidade - mutante, inacabada. Portanto, a condição de deficiência de uma pessoa diante de uma situação inacessível, por exemplo, não representa totalmente a sua diferença.

Além da diferença deleuziana, a PNEEPEI (BRASIL, 2008) embasou as discussões docentes sobre estratégias de ensino, uma vez que esse documento apresenta as diretrizes para o desenvolvimento de um trabalho educacional inclusivo.

O referencial adotado nos encontros de formação ajudou os professores a entender os fundamentos e práticas de uma escola inclusiva — ambiente que acolhe a todos, sem exceções; espaço pensado a partir do direito que cada aluno tem de participar das mesmas atividades que os demais, mas se desenvolvendo segundo seus interesses e curiosidades. Em outras palavras, conforme Mantoan (2008), segundo a sua própria diferença.

\section{Caminho metodológico da formação}

Diante da dificuldade dos professores para identificar aspectos excludentes do seu trabalho, o formador sugeriu a filmagem de trechos das aulas que seriam analisados posteriormente nos encontros formativos. 
Pesquisas brasileiras e de outros países já têm desenvolvido essa técnica de registro. Segundo Lanuti (2019, p. 92):

No Japão, ela recebe o nome de Jyugyo Kenkyu; nos Estados Unidos, Lesson Study; em Portugal e na Espanha é denominada Estudos de Aula. No Brasil, tem-se utilizado os termos Ensino Exploratório ou Tematização da Prática - este último defendido pelas pesquisadoras Telma Weisz e Ana Sanchez (2011).

Inicialmente, houve a resistência de alguns professores devido ao medo do julgamento dos colegas. No entanto, alguns aceitaram o desafio e, com o próprio celular, filmaram os alunos na realização das tarefas propostas (com a devida autorização dos seus responsáveis) ${ }^{3}$.

As aulas não eram filmadas integralmente, apenas os trechos que os próprios professores escolhiam para serem apresentados e analisados na formação. A orientação do formador/pesquisador foi para que eles filmassem momentos que poderiam ajudar o grupo a identificar as questões problemáticas relacionadas à inclusão escolar. São exemplos de elementos que compuseram as filmagens e que foram analisados pelo grupo nos encontros de formação: o momento em que os alunos (ou grupos deles) falavam sobre o que pensavam a respeito de um determinado problema; as informações buscadas por eles para entender um conteúdo; como as turmas utilizavam os materiais disponibilizados e, também, o modo como o professor conduzia a aula.

Ainda que alguns professores tivessem aderido à tematização da prática, a maioria deles se sentia desconfortável para se expor em frente à câmera. A timidez e a insegurança diante dos colegas dificultavam o relato das percepções docentes e reais dúvidas sobre o próprio trabalho. Além disso, muitos professores também relataram que os alunos não se comportavam naturalmente enquanto eram filmados.

O formador/pesquisador percebeu que a análise dos trechos filmados das aulas, por ocorrer de modo fragmentado, estava restrita à ação empírica, aos recursos e materiais utilizados, ao comportamento dos estudantes, ou seja, àquilo que podia ser observado - a experiência puramente pragmática. Diante dessa constatação,

\footnotetext{
${ }_{3}^{3}$ Pesquisa aprovada pelo CEP da UNICAMP. Número CAAE: 54026216.6.0000.5404 
procurou auxiliar os professores a entender que a intencionalidade docente ao desenvolver uma aula é mais importante do que qualquer outro fator.

Ao estudar a proposta de Weisz e Sanchez (2011), o formador/pesquisador descobriu que, além da filmagem, as autoras propuseram a narratividade sobre aula. Essa ideia encantou a todos os participantes! Com o objetivo de auxiliar os professores a entenderem que a experiência educacional está centrada na imprevisibilidade, na produção de sentidos para o que se vive, ou seja, está além dos ideais pragmáticos, o formador sugeriu a escrita de narrativas sobre as aulas.

A narratividade, conforme refere Lanuti (2019), diz respeito ao modo pelo qual cada pessoa estuda e organiza suas experiências, considerando elementos objetivos (fatos e materiais) e subjetivos (o que advém da interpretação dos fatos). Tal organização prevê uma atualização dos fatos vividos, o que provoca um deslocamento de sentidos. Narrar é, portanto, um exercício reflexivo, subjetivo que faz surgir um acontecimento, isto é, o movimento de produção de uma singularidade, o surgimento de uma diferença, sempre inédita, conforme pensou Deleuze (2000).

O acontecimento pode até estar relacionado a um ato empírico, mas não se resume à sua materialidade. É, portanto, aquilo que transcende o material e a ação realizada; está relacionado ao sentido que criamos ao que nos passa e nos transforma. A narratividade é produtora de acontecimentos e, por meio dela, é possível que uma formação contribua para mudanças nas concepções e práticas pedagógicas.

Nesse sentido, narrar vai além da análise de um momento fragmentado (como ocorria na filmagem das aulas), pois mobiliza sentimentos, sensações, desejos, intencionalidades, dentre outros elementos, ignorados pelo pragmatismo da escola.

Para Dewey (1959), um dos fundadores do Pragmatismo, a experiência compreende alguns princípios, dentre os quais: i) a elaboração de uma hipótese para tornar um problema mais coerente, harmonizando-se com uma série maior de circunstâncias; ii) tomar como base a hipótese concebida, para o plano de ação aplicável ao existente estado de coisas e iii) "fazer alguma coisa para produzir o resultado previsto e pôr em prova a hipótese” (1959, p. 164). Nessa perspectiva existe a pretensão de que um problema possa ser resolvido a partir da formulação de hipóteses que tenham coerência com instâncias maiores, ou seja, os pressupostos, as possibilidades já determinadas. 
A experiência entendida deste modo é reduzida a um experimento que pode ser controlado, verificado e que, necessariamente, pretende ter um resultado aplicável à prática. No campo educacional, a experiência convertida em experimento tem influenciado os processos de formação docente, nos quais são comumente apresentadas ações de ensino "bem-sucedidas" para serem reproduzidas. Nesse movimento de conversão, desconsidera-se a imprevisibilidade do ato pedagógico e determina-se o que deve ser aprendido pelos estudantes. Assim sendo, a lógica pragmática pouco contribui para a construção de uma escola inclusiva.

Os resultados obtidos com a narratividade dos professores na referida pesquisa de Doutorado, aqui analisada, são tratados a seguir.

\section{Alguns resultados}

As discussões realizadas nos encontros semanais foram baseadas nas narrativas produzidas pelo grupo docente. Ao escreverem a respeito das aulas, os professores conseguiram, aos poucos, relacionar a diferença, conforme concebida por Deleuze $(1988 ; 2000)$ às situações cotidianas que vivenciavam com suas turmas.

O formador do grupo, em outras ocasiões, já havia conversado com todos a respeito da adaptação das atividades que eles realizavam para alguns alunos. No entanto, embora os próprios estudantes questionassem tal prática, os professores insistiam em realizá-la.

O relato da professora Ana despertou a atenção do grupo. Ao narrar suas experiências com a turma do $4^{\circ}$ ano, ela escreveu que gostaria de aprender a ensinar sem ter que adaptar a aula. Para Ana, a adaptação é necessária quando não são preparadas as aulas pensando em cada aluno, na turma toda, mas em alguns, e as crianças percebem isso. A reflexão narrativa realizada por ela revelou que, ao escrever sobre o seu modo de organização das aulas, Ana percebeu que a adaptação do currículo aos alunos considerados com deficiência é excludente, pois é uma diferenciação pela deficiência, conforme traz a Convenção da Guatemala (1999) e a PNEEPEI (BRASIL, 2008) — textos estudados na formação. Quando indagada pelo formador, Ana disse que ao narrar as suas experiências, se deu conta de que "a

\footnotetext{
${ }^{4}$ Promulgado, no Brasil, pelo Decreto n 3.956, de 8 de outubro de 2001(BRASIL, 2001). 
inclusão escolar tem a ver com atividades diversificadas (e não adaptadas) para que cada estudante tenha a oportunidade de aprender".

Percebeu-se que a escrita possibilitou o que a análise das cenas filmadas não alcançou: o entendimento de que em uma aula inclusiva o ensino não é pensado para alguns alunos e adaptados aos demais, mas são desenvolvidas situações nas quais cada estudante participa a seu modo.

Aos poucos, a quantidade de adeptos à prática de narrar as experiências pedagógicas aumentou. A professora Rosa narrou o que pensava a respeito de instrumentos uniformizadores, como as avaliações externas que, segundo ela, desconsideram o que acontece em cada aula. Em conversa com o formador/pesquisador, ela relatou que ao escrever sobre o desempenho dos alunos nestas avaliações, constatou a contradição que existia na escola em "defender a inclusão, mas nivelar as turmas a partir dos erros e acertos em uma avaliação de larga escala".

A professora Melina escreveu sobre a confusão que fazia ao entender o AEE como um reforço escolar. Em um dos relatos, ela registrou ter percebido que, ao escrever sobre suas dificuldades pedagógicas, esperava que o professor do AEE executasse um reforço escolar, ensinando conteúdos. A professora percebeu, a partir do estudo da Política de 2008 que esta não seria a função do AEE.

O relato de Melina evidenciou a importância da narratividade para o processo de formação. À medida que, ao escrever, deu-se conta da confusão que fazia quanto à função do AEE, ela teve a oportunidade de repensar sobre o trabalho que desenvolvia na escola.

Neide, uma professora do $1^{\circ}$ ano, relatou em um dos encontros de formação que, para narrar suas experiências, oralmente ou de forma escrita, era preciso estudar, organizar as ideias, rever o modo de organizar a aula e, com isso, questões antes ignoradas (como a categorização dos alunos pela nota) poderiam ser problematizadas.

Ao analisar as narrativas, o pesquisador/formador percebeu que o hábito de adaptar atividades para alguns estudantes foi sendo, aos poucos, modificado. Passeios, entrevistas, experiências, seminários e outras tarefas na quais cada aluno reconhecia a sua habilidade, substituíram a adaptação. 
A professora Fabiana, por exemplo, desenvolveu uma aula-passeio com a turma, na tentativa de promover a participação de todos os estudantes. $\mathrm{Na}$ atividade prática desenvolvida, cada estudante pôde fazer observações sobre os números das casas do bairro da escola. Cada um tirou suas próprias conclusões sobre números pares e ímpares, ordem crescente e decrescente, antecessor e sucessor e, depois, compartilhou com os colegas.

Para Fabiana e todo o grupo docente que participou da formação, a narratividade provocou a construção de experiências que, por estarem além do pragmatismo, não se resumiam à ação pedagógica observável, a supostos resultados imediatos do ensino, como a nota em uma avaliação. A experiência da narratividade possibilitou aos professores uma reinterpretação do ensino, com base na consideração da singularidade de cada um dos alunos.

\section{Conclusões}

Os achados apresentados neste artigo, sobre as duas experiências formativas, trouxeram como ponto comum a valorização da narratividade dos professores envolvidos.

Na pesquisa desenvolvida por Baptista (2018), partiu-se de registros narrativos (depoimentos, entrevistas etc.) das professoras para criar outras narrativas e analisar a atuação destas na construção do TNR. O que ficou evidente com essa pesquisa foi que um espaço de formação precisa deixar o professor à vontade para expor suas dúvidas e dificuldades sem julgamentos dos demais, principalmente, em relação a um serviço tão complexo como o AEE.

Lanuti (2019), em sua pesquisa, reconheceu que por meio da narratividade os professores conseguiram expor, abertamente, os problemas que vivenciavam em relação à inclusão. Entendeu, ainda, que a subjetividade precisa ser considerada na formação docente e que a narratividade é um meio de expressar aspectos que são, muitas vezes, ignorados nas formações.

Além da valorização da narratividade nos processos formativos, foi fundamental para as duas pesquisas desenvolvidas o embasamento teórico na PNEEPEI (BRASIL, 2008), pois tal dispositivo legal trouxe aos professores os fundamentos e práticas de uma escola inclusiva. 
Ambas as pesquisas demonstraram que os processos formativos de professores precisam considerar a subjetividade dos mesmos: seus saberes prévios, realidades locais, medos e desejos. A narratividade, mais do que um recurso metodológico das pesquisas, foi o meio pelo qual a subjetividade docente veio à tona e pôde ser analisada. Se pela narratividade, o professor não pode ser considerado um sujeito abstrato, universalizado, cada aluno também deve ter a sua singularidade valorizada, desde o planejamento ao desenvolvimento e avaliação do ensino.

\section{Referências}

BAPTISTA, M. I. S. D. Danças no TNR: movimentos de professores em formação continuada. 2018. 200f. Orientador: Maria Teresa Eglér Mantoan. Tese (Doutorado em Educação) — Faculdade de Educação, Universidade Estadual de Campinas, Campinas, 2018.

BENJAMIM, W. Magia e técnica, arte e política: ensaios sobre literatura história da cultura. 7. ed. São Paulo: Brasiliense, 1994.

BRASIL. Decreto n ${ }^{\circ} 3.956$, de 8 de outubro de 2001. Promulga a Convenção Interamericana para Eliminação de Todas as Formas de Discriminação contra as Pessoas com Deficiência. Guatemala: 2001.

BRASIL. Ministério da Educação. Política Nacional de Educação Especial na Perspectiva da Educação Inclusiva. Brasília: MEC/SEESP, 2008.

CLANDININ, D. J.; CONNELLY, F. M. Pesquisa narrativa: experiência e história em pesquisa qualitativa. Trad. Grupo de pesquisa narrativa e educação de professores Ileel/UFU. 2 ed. Uberlândia: UDUFU, 2015.

DELEUZE, G. Diferença e repetição. Rio de Janeiro: Graal, 1988.

DELEUZE, G. Lógica do sentido. 4 ed. São Paulo: Perspectiva, 2000.

DEWEY, J. Democracia e Educação: introdução à filosofia da educação. Trad. Godofredo Rangel e Anísio Teixeira. 3 ed. São Paulo: Nacional, 1959.

LANUTI, J. E. O. E. O ensino de Matemática - sentidos de uma experiência. 2019. 127 f. Orientador: Maria Teresa Eglér Mantoan. Tese (Doutorado em Educação) — Faculdade de Educação, Universidade Estadual de Campinas, Campinas, 2019.

LARROSA, J. Tremores: escritos sobre experiência. Trad. Cristina Antunes e João Wanderley Geraldi. Belo Horizonte: Autêntica Editora, 2015.

MANTOAN, M. T. E. Ensinando a turma toda: as diferenças na escola. In: MANTOAN, M. T. E. (Org.) O desafio das diferenças nas escolas. Petrópolis: Vozes, 2008. p. 59-67. 
MANTOAN, M. T. E. Igualdade e diferenças na escola: como andar no fio da navalha. In: MANTOAN, M. T. E.; PRIETO, R. G.; ARANTES, V. A. (Org.). Inclusão escolar: pontos e contrapontos. São Paulo: Summus, 2006. p. 15-30.

MORAES, A. A. de A. Histórias de leitura em narrativas de professoras: uma alternativa de formação. 1999. 212f. Orientador: Ezequiel Theodoro da Silva. Tese (Doutorado em Educação) - Faculdade de Educação, Universidade Federal de São Carlos, São Carlos, 1999.

ROCHA, H. V.; BARANAUSKAS, M. C. Design e Avaliação de Interfaces Humano - Computador. Campinas: Nied-Unicamp, 2003.

WEISZ, T.; SANCHEZ, A. O diálogo entre o ensino e a aprendizagem. 2. ed. São Paulo: Ática, 2011.

RECEBIDO: 27/05/2020

APROVADO: 08/04/2021
RECEIVED: 05/27/2020

APPROVED: 04/08/2021
RECIBIDO: $27 / 05 / 2020$

APROBADO: 08/04/2021 